\title{
Blade shape and thickness influence of multi-blade cutting tool during axial impact to the extruded aluminum tube
}

\author{
B. Mashadi*, J. Marzbanrad**, A. Afkar*** \\ *School of Automotive Engineering, Iran University of Science and Technology, Tehran, Iran, \\ E-mail: b_mashadi@iust.ac.ir \\ **School of Automotive Engineering, Iran University of Science and Technology, Tehran, Iran, \\ E-mail:marzban@iust.ac.ir \\ ***School of Automotive Engineering, Iran University of Science and Technology, Tehran, Iran, E-mail: afkar@iust.ac.ir \\ cross $^{\text {ref }}$ http://dx.doi.org/10.5755/j01.mech.22.3.15251
}

\section{Introduction}

Exploitation of steam pipelines during start-up, hydraulic tests overloads and other emergencies, the strains reach dangerous values at times exceeding allowable limits. In most cases, such loads are met in the zones of stress concentration also cracks and welded joints zones. Increase of loading frequency in a set of forth, above dangerous zones, causes fast growth of fatigue crack in construction, resulting its failure. The evaluation of such situations needs to meet criteria of material resistance to crack growths as a characteristic of fracture.

Thin-walled beams are widely used as crash absorbers in the automotive chassis. Such kinds of structures are frequently used in the vehicle front parts. These parts play an important role in energy absorption during frontal crashes. Thin-walled tubes absorb kinetic energy of the crash via plastic deformation to protect vehicle occupants. These elements are specifically designed to absorb high amounts of energy during a crash to ensure passenger cabin integrity and hence the passenger safety. The use of lightweight materials has increased recently to reduce the weight of vehicle body and the fuel consumption [1]. Mul-tiple alternatives such as advanced high-strength steels, aluminum or magnesium alloys, and composite materials have been proposed to replace mild steel applications in the automotive structure [2]. Due to its low weight and being a corrosion resistor, aluminum alloy is a good alter-native that can be recycled with much less required energy than that needed to produce primary aluminum. The pros-pect shows that for example, in Europe, the aluminum consumption will face the increase of 30\% until 2020 as shown in Fig. 1 [3]

The energy absorption and the maximum impact load of an aluminum crash box during a crash depend on many parameters such as geometry, strain-rate sensitivity, plastic deformation history of metalwork, porosity of materials, temperature during crash, boundary conditions and impact energy (mass and velocity of the striker). Splitting circular metal tubes is an efficient energy absorption method to dissipate undesirable energies in many structures such as automotive ones. Use of splitting process has many advantages in comparison to other energy absorber systems since there are various failure mechanisms in the whole process such as bending, stretching and tearing.

Alavi Nia and Haddad Hamedani [4] investigated deformations and energy absorption capacity of thin-walled tubes with various sections shapes (circular, square, rectangular, hexagonal, triangular, pyramidal and conical) both experimentally and numerically. The tubes have the same volume, height, average section area, thickness and material and are subjected under axial quasi static loading. The results of simulations are in good agreement with the experimental data and show that the section geometry has considerable effect on the energy absorption. The circular tube has the most energy absorption capacity and the most average force among all investigated sections. Reid [5] studied different deformation modes such as splitting, inversion and folding in circular tubes subjected to axial loadings. It was shown that plastic deformation is a major mechanism for dissipating kinetic energy. The mechanisms which involve fracture such as splitting process can use plastic deformation as a good energy absorber.

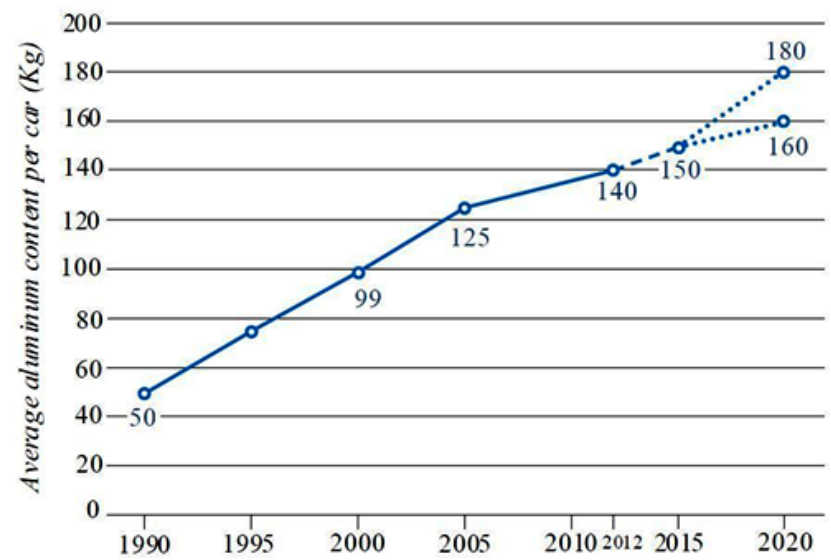

Fig. 1 Evolution of the average aluminum content per car produced in Europe [3]

Zhou and Wang [6] studied the coalescence splitting mechanism of crack-weakened brittle materials subjected to compressive load by using the improved near crack line analysis method and simplification of crack development mechanism. They presented some analytical relations to estimate stress components near the crack line. Cheng and Altenhof [7] developed and used a cutting de-vice in Quasistatic axial compressive tests of square cross section AA6061-T6 extrusions to generate a cutting de-formation mode of the extrusions. For the extrusions which experienced the cutting deformation mode, two energy dissipating mechanisms were observed, namely, a cutting deformation mechanism and pedalled sidewall outward bending mechanism. The bending energy absorption mechanism accounted for approximately $25 \%$ of the total energy absorption. 
Jin et al. [8] studied the load/displacement and energy-absorption characteristics of AA6061-T6 round extrusions under a cutting deformation mode via experimental testing. Tube length appeared to have no significant influence on the load/displacement response of the extrusions, which experienced the cutting mode of deformation. The average crush force efficiency for extrusions, which experienced the cutting mode of deformation, was approximate 0.95 independent of tube length. The average CFE of specimens which experienced progressive folding and global bending deformation modes were 0.66 and 0.20 , respectively. Majumder et al. [9] investigated experimentally a cutting deformation mode of AA6061 T4 and T6 round extrusions with two different wall thicknesses of 1.587 and $3.175 \mathrm{~mm}$ under quasi-static loading conditions. Clean cutting behavior was observed for the extrusions with a T6 temper and wall thickness of $1.587 \mathrm{~mm}$ and for extrusions with a T4 temper and wall thickness of $3.175 \mathrm{~mm}$. Jin and Altenhof [10] proposed an analytical deformation model for axial cutting of circular tubes by using a cutter with multiple blunt blades and compared their model with experimental measurements. The effect of the friction force was included in the proposed solution and the steady-state axial cutting force was determined through the use of the principle of virtual power.

Yuen et al. [11] demonstrated the experimental data on the axial splitting of circular aluminum extrusions under a blast loading condition using a cutting tool and deflector configurations were performed with a good de-gree of repeatability and controllability. The thick-walled extrusions exhibit better repeatability and controllability during the tests. The increase in wall thickness provided more contact surface area between the extrusions and the blade hence making them less susceptible to misalignment. In general, the length of cut depth was observed to increase with the increase of charge mass used and decreased with the increase in wall thickness. Niknejad et al. [12] derived some theoretical relations to predict the axial force during the splitting process on circular metal tubes. They introduced a new theoretical model of defamation that divides the splitting process into five different stages. This study showed that when the semi-angle of die increases, the maximum splitting force and the steady force increase. By increasing the number of initial slits, tube diameter and tube wall thickness, the splitting force increases, too. Also, the axial load of the splitting process is enhanced when the initial slits length decreases.

Marzbanrad et al. [13] considered the stress-strain sensitivity effect on box behaviour during a crash by creating elastic and plastic boundary conditions instead of rigid boundary conditions on the bottom of a crash box. In addition, the effect of elastic and plastic boundary conditions on the energy absorption of circular tubes under impact force is numerically investigated. The ductile failure criterion is employed to accurately obtain crashworthiness simulation results. Results reveal that the use of elastic boundary can change deformation mode and decrease the maximum impact force. Generally, there are two methods to develop rupture process in tubes:

- use of cone-shaped rigid rod;

- use of cutting tools.

Occurs by the conical rod, this kind of process has its own disadvantages:
- crush force efficiency reduction due to high maximum force at the beginning of process;

- unpredictable petal numbers and rupture path;

- variable amount of energy absorption and non-repeatability of the process.

Numerous problems with using this method as an energy absorption system in vehicles during collision, because of heavy weight and high required space above the conical rod which must be embedded inside the vehicle.

Rupture with the help of cutting tools is studied in two ways. One is the case when the load is applied to the cutting tool and the tool moves while the tube is stationary; the other one is when the cutting tool is fixed and the impact strikes the tube (the tube is moving). The second case is less applicable in comparison to the first one because of packaging problems and cutting tool fixing. Tube rupture by the multi-blade cutting tool is a limited studied subject. The effects of cutting blade's shape and thickness on the effective parameters of energy absorption are not investigated. In this paper, numerical modelling of the impact of 12 kinds of 4blades cutting tool to the aluminum tube is studied and effects of the cutting blades' shape and thickness on the energy absorption parameters are analyzed during the impact

\section{Modeling}

In 2004, a group of researchers in Germany's BMW automobile company, directed by Hooputra, proposed a comprehensive approach for predicting a component failure based on macroscopic strains and stresses [14]. This approach requires the use of a number of different failure mechanism representations, such as necking (due to local instabilities), as well as ductile and shear fracture. All the failure criteria have been developed in a way to include the effect of nonlinear strain paths. They experimentally obtained the material parameters of aluminum alloy EN AW7108 T6 for quasi-static and dynamic cases, and using these criteria could accurately predict the failure of aluminum parts. The Hooputra's ductile fracture criterion is based on Kolmogorov's mathematical model [15], and represents the equivalent strain as a function of the stress triaxiality. Regarding the non-uniform effect of increasing the equivalent strain, affected by the stress triaxiality growth, three dependent parameters are considered for the isotropic materials. For these materials, the criterion is defined as:

$$
\begin{aligned}
& D=\int_{0}^{\bar{\varepsilon}_{f}} \frac{d \bar{\varepsilon}}{\bar{\varepsilon}_{f}(\eta)} ; \\
& \eta=\frac{\sigma_{m}}{\bar{\sigma}} ; \\
& \bar{\varepsilon}_{f}(\eta)=a e^{-c \eta}+b e^{c \eta},
\end{aligned}
$$

where $\bar{\varepsilon}_{f}, \sigma_{m}, \bar{\sigma}$ and $\eta$ are the fracture equivalent strain, mean stress, Von Mises equivalent stress and the stress triaxiality, respectively. Furthermore, $D$ indicates damage variable, which changes from raw material to ruptured material. Symbols $a, b$ and $c$ are the material parameters which are experimentally extracted from waisted tensile specimen [16], Erichsen's cupped test, and three-point bending test of double chamber extrusion component. In the above-mentioned tests, the values of stress triaxiality are $1 / 3,2 / 3$ and 
$1 / \sqrt{3}^{10} 1 /$, respectively.

ABAQUS/Explicit software is used to perform the numerical simulations. Four-node shell elements with reduced integration (ABAQUS S4R) are employed to describe the circular tube tests with aluminum alloy EN AW-7108 T6. The isotropic hardening properties (true stress vs. plastic strain) of this material are shown in Fig. 2 [14].

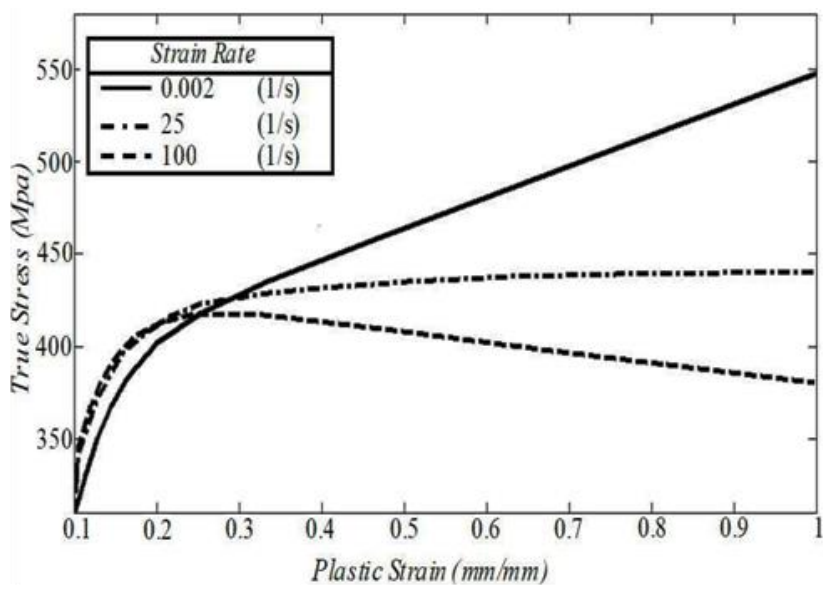

Fig. 2 Stress-strain curve at different strain rates [14]

This model was previously used for impact of aluminum alloy EN AW-7108 T6 tube with a circular cross section and for aluminum alloy 6063-T4 tube with a square cross section during folding and was verified with the help of experimental results $[13,17]$. A sample of model results in comparison to experimental results is shown in Fig. 3.

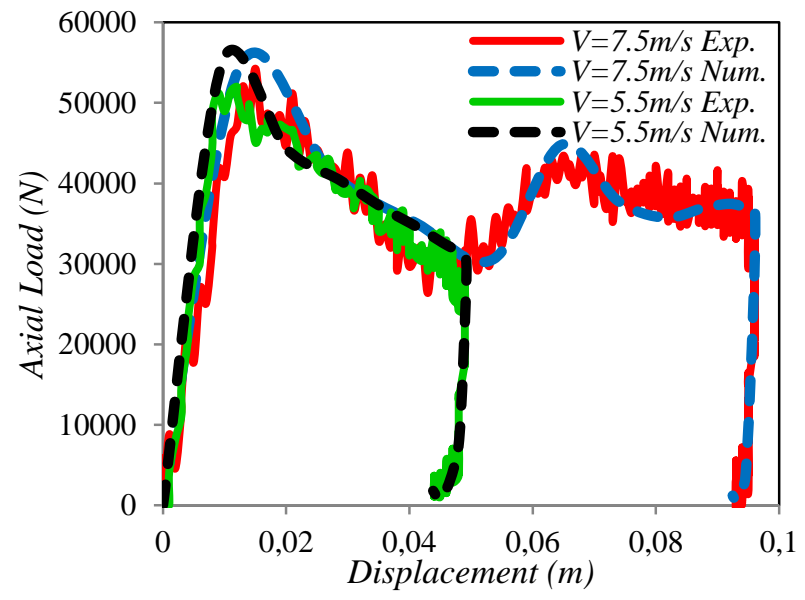

Fig. 3 Comparison diagrams of model and experimental results of force versus displacement for tube axial impact with two velocities of 7.5 and $5.5 \mathrm{~m} / \mathrm{s}$ during folding [17]

Moreover, this model is used for quasi-statically tube cutting simulation with cutting tools based on experimental study of Majumder [9]. To make this model of cutting tools, similar dimensions of four-blade (model A) tools of Majumder is used. Tube length is $300 \mathrm{~mm}$, its external diameter is $50.8 \mathrm{~mm}$, its thickness is $3.175 \mathrm{~mm}$ and is made up of aluminum alloy AA6061-T4. Comparison diagram of axial force versus displacement during quasi-statically cutting by the cutting tool is shown in Fig. 4. As it is seen, the model results have proper accuracy in comparison to the experimental study.

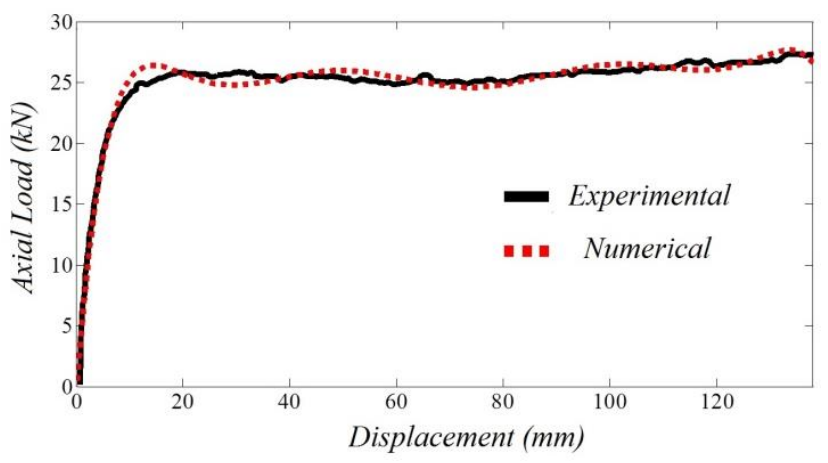

Fig. 4 Comparison diagram of model and experimental results [9] of force versus displacement for quasi-statically tube cutting with the help of cutting tools

In this study, the effects of cutting tools with different cutting blades' shapes and thicknesses are investigated during axial impact to the aluminum tube. Twelve blades kinds of different cutting tools are considered for the 4-blades cutting tools (Fig. 5) including four shapes with three different thicknesses (Fig. 6). Cutting tools of shape 1 and shape 2 are with inclined openings, like an equilateral trapezoid with heights of 3 and $9 \mathrm{~mm}$, respectively. Cross section of the cutting blade of shape 3 is semi-circle and the cutting blade of shape 4 has two vertical corners. Each of these blades shape is studied with three thicknesses of 3, 4.5 and $6 \mathrm{~mm}$ during tool impact to the aluminum tube. The depth of both cutting tools is the same and equals to $30 \mathrm{~cm}$.

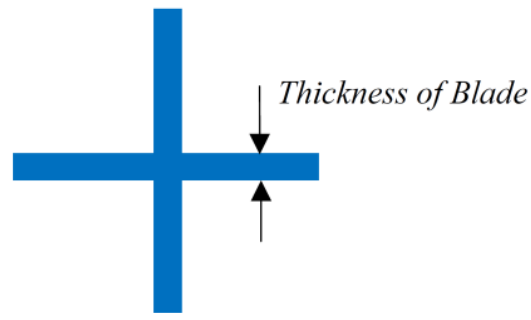

Fig. 5 Front view of cutting tool with 4 blades

All the strikers are regarded as a point mass of $50 \mathrm{~kg}$ with initial velocity of $V=10 \mathrm{~m} / \mathrm{s}$ in one direction. Due to the striker's rigidity assumption and also restraining it in all directions except the axial one (a longitudinal direction), the mass is considered as lumped for simplicity in modeling. The contact between tube and striker is defined as the surface-to-surface interaction with a friction coefficient of 0.2 . Besides, double surface self-contact is defined considering the whole tube surface with a friction coefficient of 0.15 [14]. The material is strain-rate-sensitive aluminum alloy (EN AW-7108 T6) with Young modulus and mass density of $E=70 \mathrm{GPa}$ and $\rho=2700 \mathrm{~kg} / \mathrm{m}^{3}$, respectively. The tube dimension include: diameter of $D=50 \mathrm{~mm}$, length of $L=300 \mathrm{~mm}$ and wall thickness of $t=2.0 \mathrm{~mm}$.

Frequency parameters are used to estimate the energy absorption capability of thin-walled tubes. Some of the most important parameters which are obtained in this study are:

- total energy absorption:

$E_{\text {Absorbed }}$ is defined as the tube external work which 
can be calculated as:

$$
E_{\text {Absorbed }}=T E A=\int P(\delta) d \delta==\sum_{i=2}^{N-1} P_{i}\left(\frac{\delta_{i+1}-\delta_{i-1}}{2}\right),
$$

where $P(\delta)$ is a function of crash load based on the tube displacement $(\delta)$. In fact, the area under the force-displacement diagram must be calculated to obtain total energy absorption;

- peak crush force:

Peak crush force is demonstrated by $P_{\operatorname{Max}}$ and is the maximum force which is applied axially to the part.
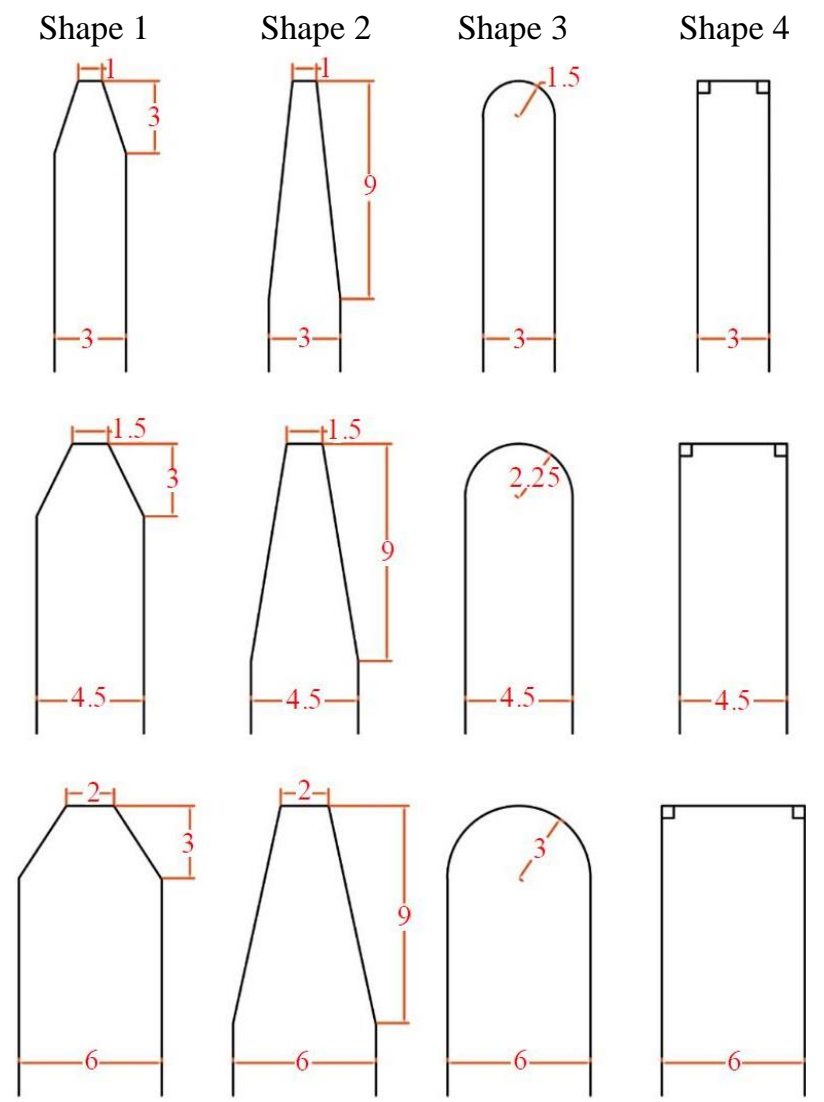

Fig. 6 Front view of the cutting blades of the 4-blades tools with different shapes and thicknesses

- mean crush force:

$P_{m}=\frac{\sum_{i=2}^{N-1} P_{i}\left(\frac{\delta_{i+1}-\delta_{i-1}}{2}\right)}{\delta_{t}}$,

which is obtained via division of total energy absorption to total crush displacement $\left(\delta_{t}\right)$;

- crush force efficiency $(C F E)$ :

$C F E==\frac{P_{m}}{P_{M a x}}$

- specific energy absorption (SEA):

$S E A=\frac{E_{\text {Absorbed }}}{m}$, where $m$ is the tube mass which absorbs energy during impact.

\section{Results and discussion}

Fig. 7 shows damage variable distribution of the Hupitra's D ductile damage criterion from zero (intact) to one (complete damage). The modeling belongs to the case where the aluminum alloy tube is relied to a flat rigid plate from one side and is impacted by the 4-blades rigid cutting tool, axially, with the velocity of $10 \mathrm{~m} / \mathrm{s}$. This figure is illustrated for tools with shapes 1 to 4 with blade thickness of $3 \mathrm{~mm}$. The created leaves by the cutting tools of shapes 1 and 3 don't change much except along the tube cutting paths. Due to greater height of the trapezius of shape 2 relative to shape 1 (tool's blade with more incline), the leaves are bent outwards of the tube central axis which causes a kind of energy dissipation (due to bending). In opposite, for tools with cutting blade of shape 4 , the created leaves are bent inwards of the tube axis.
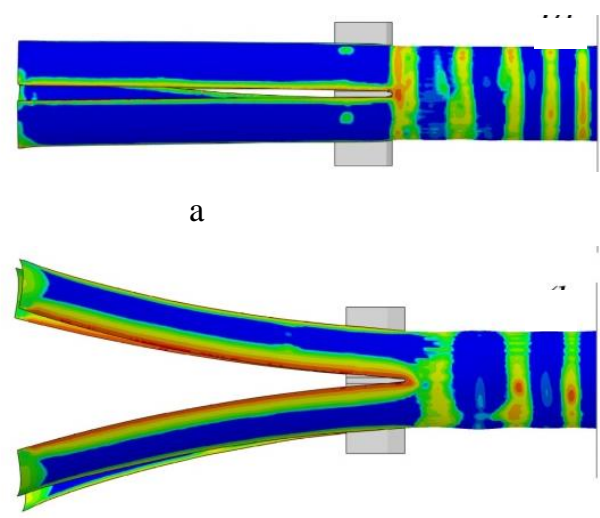

b

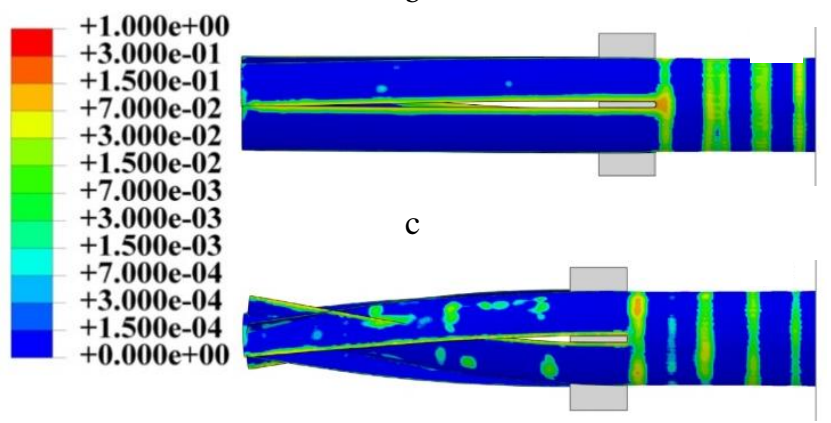

d

Fig. 7 Damage variable distribution of $D$ damage criterion from zero (intact) to one (complete damage) for tools' impact to the aluminum tube, axially, with shapes: $\mathrm{a}-1 ; \mathrm{b}-2 ; \mathrm{c}-3 ; \mathrm{d}-4$ and blade thickness of $3 \mathrm{~mm}$

As it is known, the energy absorption of tube cutting process is done through three manners:

- energy absorption at the wedge area of cutting tool when the cutting wedge penetrates inside the tube sheet;

- energy absorption due to friction between cutting tool surfaces and the tube;

- energy absorption due to plastic deformation inside the tube. 


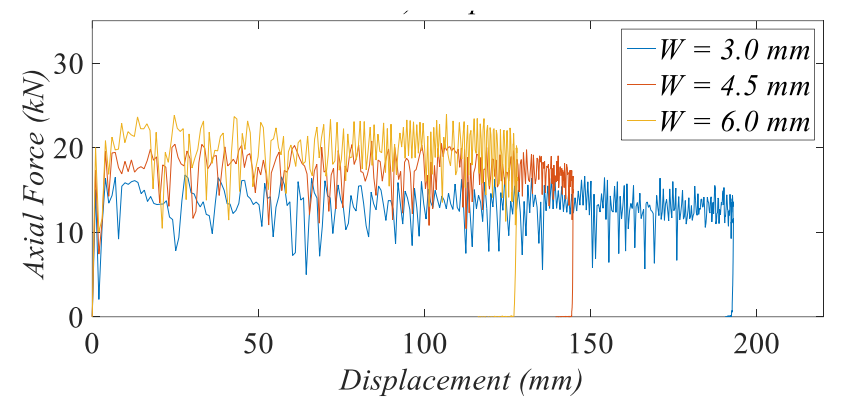

a

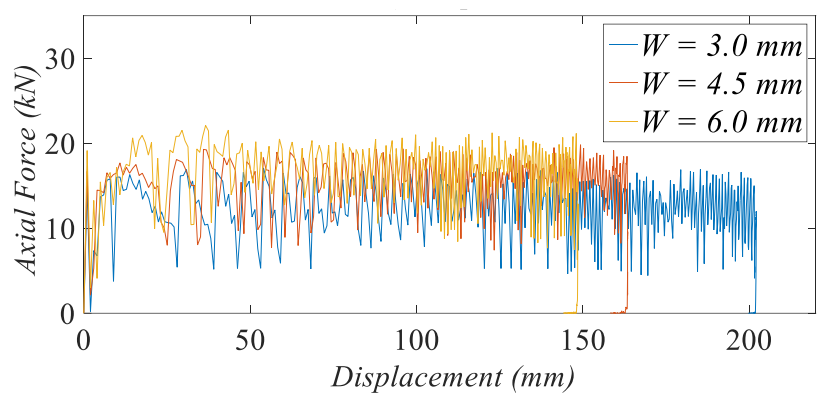

$\mathrm{b}$

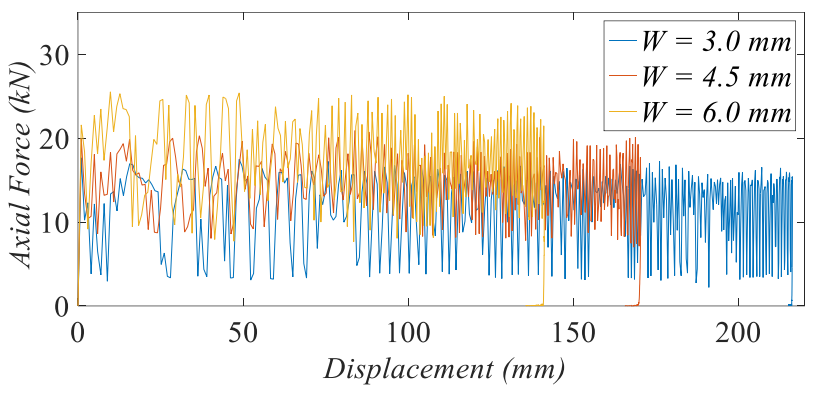

c

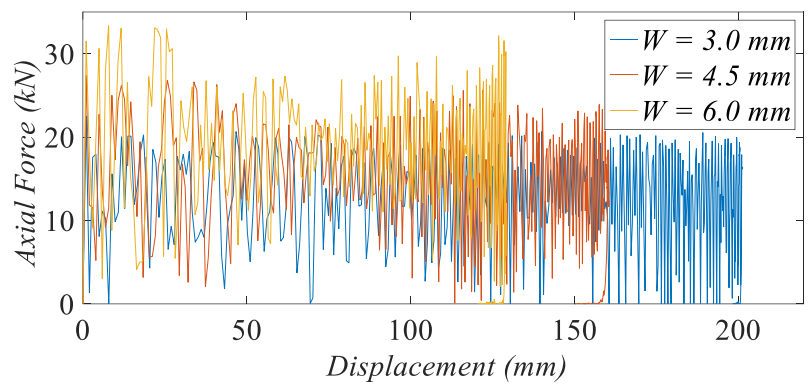

d

Fig. 8 Comparative diagrams of axial force versus displacement of the whole tube rupture process by the 4blades cutting tool with different tool blade thicknesses and shapes of: $\mathrm{a}-1 ; \mathrm{b}-2 ; \mathrm{c}-3 ; \mathrm{d}-4$

In Fig. 8, the force diagram in terms of displacement is seen during impact by the 4-blades cutting tool with four different kinds of cutting blade shapes (a to c) and each with three different thicknesses $(w=3,4,5$ and $6 \mathrm{~mm})$. As it is clear, with decrease of cutting blades' thickness, the tool's progress inside the tube increases and the force level reduces. The maximum force variations are observed for tools with cutting blade of shape 4 (two vertical corners) and after that, the tool of shape 3 (semi-circle) has the most variations. Tools of shapes 1 and 2, place at further ranks, respectively. For rupture by the tools of shape 4, the created filing width during rupture increases due to vertical corners of the cutting blade and in fact, much more of the tube is removed as strip which causes severe vibrations and increase of force variations amplitude. The impact process to the tube changes from the rupture to the cutting and the tooling progress inside the tube increases significantly and the force reduces. This is not suitable for energy absorption in a tube during impact.

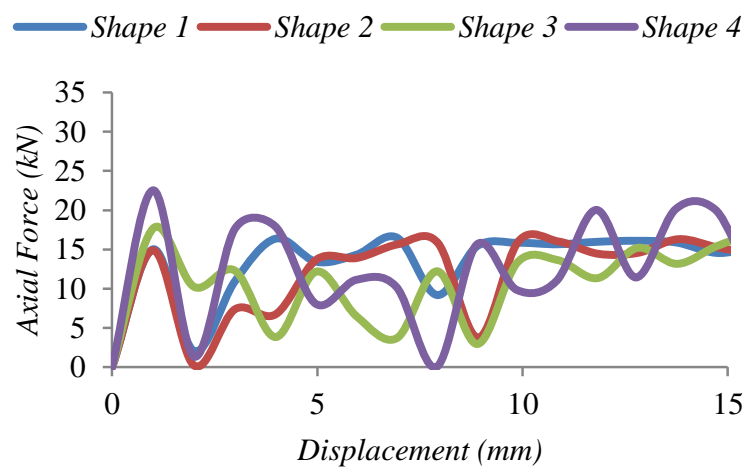

a

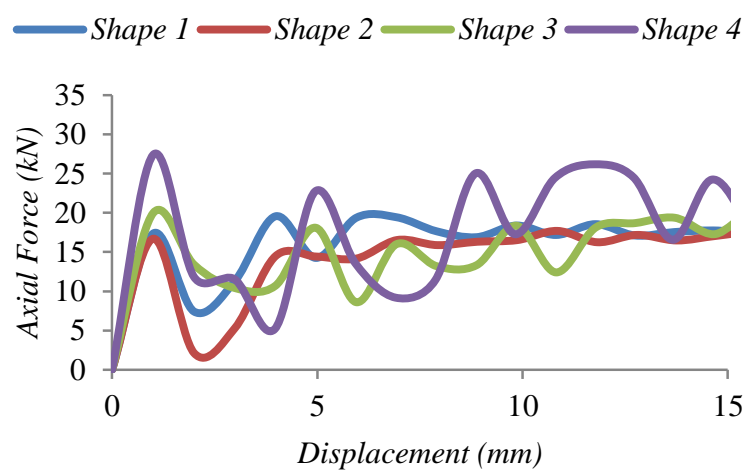

b

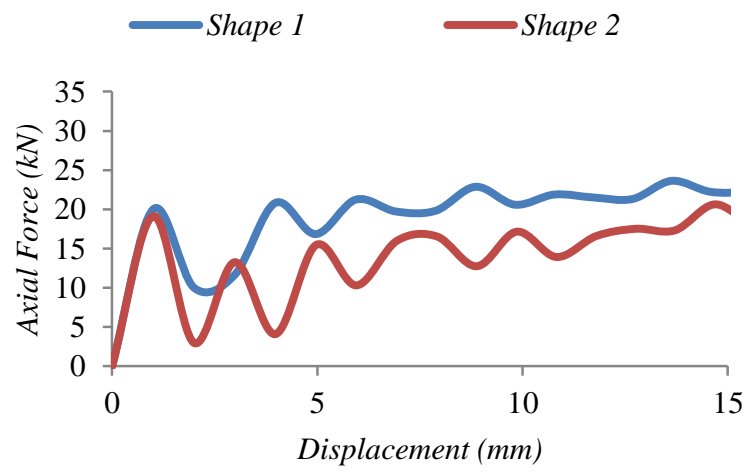

c

Fig. 9 Comparative diagrams of axial force versus displacement for the first 15 seconds of the tube rupture process by the 4-blades cutting tool with different tool blade shapes and thicknesses of: $\mathrm{a}-w=3.0 \mathrm{~mm} ; \mathrm{b}-w=4.5 \mathrm{~mm} ; \mathrm{c}-w=6.0 \mathrm{~mm}$

Fig. 9 demonstrates force diagram versus displacement during impact for the first $15 \mathrm{~mm}$ of the tool progress inside the tube. This figure shows force behavior in terms of displacement for different tooling shapes. The initial maximum force relates to the tools of shape 4 , shape 3 , shape 1 and shape 2 , respectively. The force variations increase with 
the increase of cutting blade thickness and the highest variation amplitude relates to the tool of shape 4. One of the reasons of force variations is the frictional contact between the tool and the tube. This friction helps the increase of energy dissipation and can be useful until it doesn't provide severe vibrations and the maximum force during cutting process doesn't pass the desired value. Although the tool depth is considered constant in this study, but depth increase causes increase of energy dissipation. It should be noted that increase of tool depth increases force amplitude and vibrations.

Some important parameters during the impact energy absorption including maximum displacement, maximum force, specific energy absorption and crushing force efficiency are investigated in the following. In Fig. 10, bar diagrams of the maximum displacement for four shapes of cutting tools' blade with three different thicknesses are illustrated when the tool impacts the aluminum tube with the velocity of $10 \mathrm{~m} / \mathrm{s}$. It is clear that lower maximum displacement during impact is more suitable. With thickness increase of the tool blade, the tool progress inside the tube will decrease for all cases. The lowest maximum displacement relates to the tool shape 1 and tool thickness of $6 \mathrm{~mm}$ and equals to $127.8 \mathrm{~mm}$ and the highest maximum displacement relates to the tool shape 3 and thickness of $3 \mathrm{~mm}$ and is $216.3 \mathrm{~mm}$.

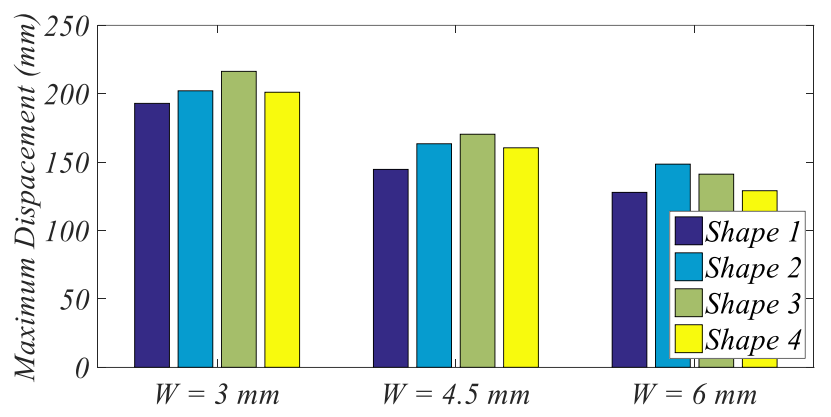

Fig. 10 Bar diagrams of maximum displacement

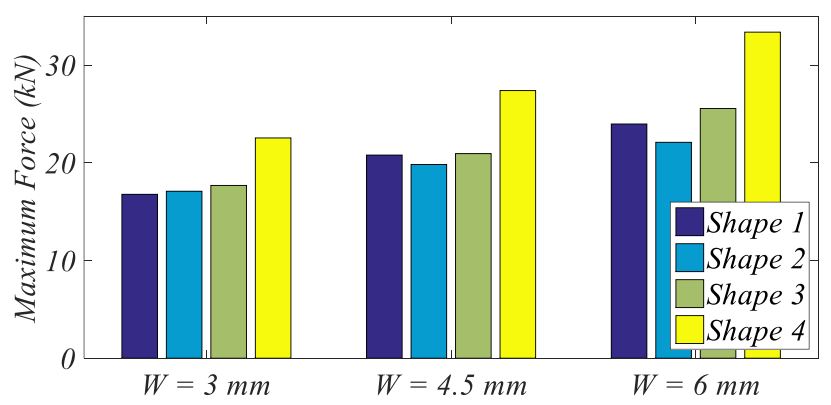

Fig. 11 Bar diagrams of maximum force

In Fig. 11, bar diagrams of the maximum force for four shapes of cutting tools' blade with three different thicknesses are shown when the tool impacts the aluminum tube. When the aluminum tube is used as energy absorber in vehicles, the inside passengers will be safer if the maximum force during the impact process is lower. With thickness increase of cutting tool's blade, the maximum force increases for all cases. For the same tool's thickness, the highest maximum force relates to the tool shape of 4 and then 3 . The lowest maximum force relates to the tool shape 1 and is 16 . $77 \mathrm{kN}$ with the tool thickness of $3 \mathrm{~mm}$. The highest maximum force relating to the tool shape 4 is $33.36 \mathrm{kN}$ with tool thickness of $6 \mathrm{~mm}$.

In Fig. 12, bar diagrams of the specific energy absorption for four shapes of cutting tools' blade with three different thicknesses are exhibited when the tool impacts the aluminum tube. Since the tool strikes the tube with the velocity of $10 \mathrm{~m} / \mathrm{s}$ for all cases and the energy absorption is calculated until the process ends, it is obvious that the energy absorptions are equal to each other. Difference of the obtained values from the numerical method with theoretical solution of Eq. $8(9.824 \mathrm{~kJ} / \mathrm{kg})$ is less than $1 \%$ and this can be another reason to the accuracy of numerical calculations.

$$
S E A_{\text {Teory }}=\frac{\frac{1}{2} m v_{\text {Initial }}^{2}-\frac{1}{2} m v_{\text {End }}^{2}}{\rho V}=\frac{\frac{1}{2} m v_{\text {Initial }}^{2}-0}{\rho(2 \pi r t L)},
$$

where $\rho$ is the tube density and $V$ is the tube volume.

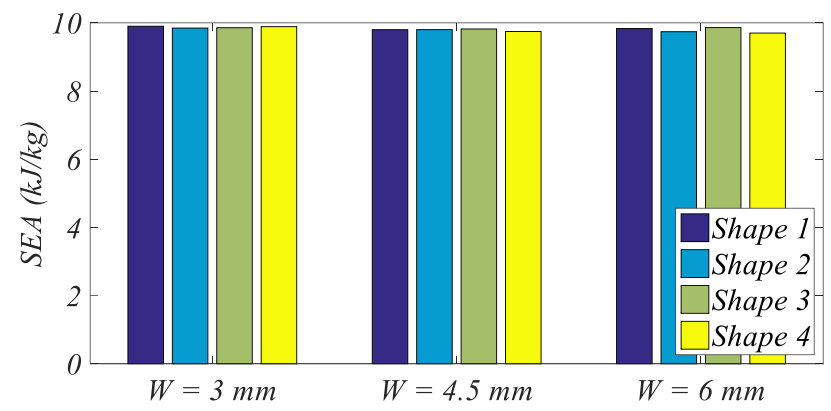

Fig. 12 Bar diagrams of special energy absorption

In Fig. 13, bar diagrams of the crushing force efficiency for four shapes of cutting tools' blade with three different thicknesses are illustrated when the tool impacts the aluminum tube. Crushing force efficiency is one of the most effective parameters in energy absorption. For the same tool thickness, descending value of the crushing force efficiency relates to the tool shapes $1,2,3$ and 4 , respectively. The maximum crushing force efficiency relates to the tool shape 4 and tool thickness $4.5 \mathrm{~mm}$ and is $55.52 \%$. As it can be seen, thickness variations of the cutting tool don't have much effect on the crushing force efficiency.

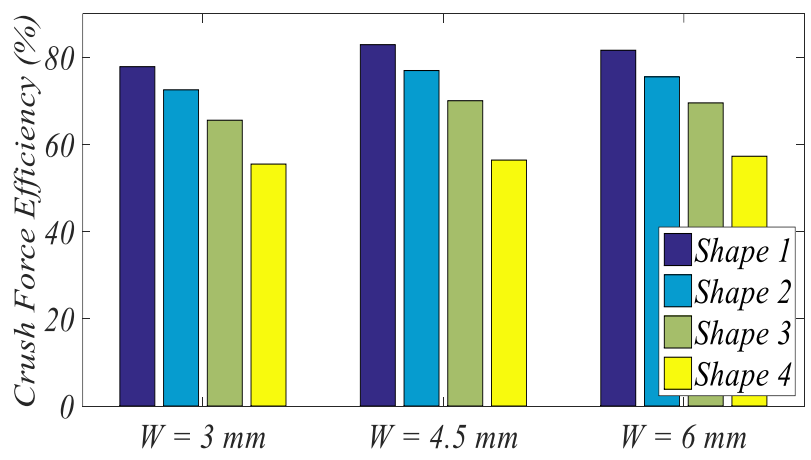

Fig. 13 Bar diagrams of crush force efficiency

At last, all the calculated effective parameters during the energy absorption are illustrated in Table 1 for different shapes and thicknesses of the tool. Besides, the energy absorption parameters for the crushing case between two flat rigid plates with the same conditions (the same impact velocity and aluminum tube) can be seen in the first row of this table. For all the energy absorption parameters, 
except the maximum displacement, the crushing conditions between two flat plates are worse than the rupture by the cutting tool. This difference is greater for the crushing force efficiency and the maximum force; and shows the rupture advantage to the crushing in the impact energy absorption.

Obtained energy absorption parameters for twelve kinds of tube rupture by the cutting tool

Table 1 and crushing between two flat plates during impact of $10 \mathrm{~m} / \mathrm{s}$

\begin{tabular}{|c|c|c|c|c|c|c|c|c|}
\hline Impact type & $\begin{array}{c}\text { Blade } \\
\text { width, mm }\end{array}$ & $\begin{array}{c}\text { Max } \\
\text { dis., } \mathrm{mm}\end{array}$ & $\begin{array}{c}\text { Max force, } \\
\mathrm{kN}\end{array}$ & $\begin{array}{c}\text { Mean force, } \\
\mathrm{kN}\end{array}$ & $\begin{array}{l}\text { TEA, } \\
\text { kj }\end{array}$ & $\begin{array}{l}\text { SEA, } \\
\mathrm{kj} / \mathrm{kg}\end{array}$ & CFE, \% & $\begin{array}{c}\text { Total time, } \\
\text { s }\end{array}$ \\
\hline Folding & - & 51.49 & 116.1 & 46.76 & 2.408 & 9.463 & 40.26 & 14.00 \\
\hline Cutting - Shape 1 & 3 & 192.9 & 16.77 & 13.05 & 2.519 & 9.901 & 77.87 & 42.30 \\
\hline Cutting - Shape 2 & 3 & 202.1 & 17.08 & 12.39 & 2.505 & 9.847 & 72.56 & 43.30 \\
\hline Cutting - Shape 3 & 3 & 216.3 & 17.68 & 11.59 & 2.508 & 9.857 & 65.58 & 44.90 \\
\hline Cutting - Shape 4 & 3 & 201.0 & 22.54 & 12.51 & 2.516 & 9.888 & 55.52 & 42.90 \\
\hline Cutting - Shape 1 & 4.5 & 144.6 & 20.78 & 17.23 & 2.493 & 9.799 & 82.92 & 31.50 \\
\hline Cutting - Shape 2 & 4.5 & 163.4 & 19.82 & 15.26 & 2.494 & 9.801 & 76.99 & 37.09 \\
\hline Cutting - Shape 3 & 4.5 & 170.3 & 20.93 & 14.66 & 2.498 & 9.820 & 70.06 & 39.50 \\
\hline Cutting - Shape 4 & 4.5 & 160.4 & 27.38 & 15.45 & 2.479 & 9.745 & 56.43 & 38.90 \\
\hline Cutting - Shape 1 & 6 & 127.8 & 23.96 & 19.56 & 2.502 & 9.832 & 81.63 & 28.90 \\
\hline Cutting - Shape 2 & 6 & 148.4 & 22.09 & 16.69 & 2.478 & 9.740 & 75.54 & 33.10 \\
\hline Cutting - Shape 3 & 6 & 141.1 & 25.55 & 17.77 & 2.509 & 9.861 & 69.56 & 30.70 \\
\hline Cutting - Shape 4 & 6 & 129.0 & 33.36 & 19.12 & 2.468 & 9.700 & 57.31 & 30.00 \\
\hline
\end{tabular}

\section{Conclusions}

In this paper, damage numerical analyses (cutting deformation and crushing) of a circular tube are carried out based on ductile damage criterion to accurately obtain crashworthiness simulation results. Generally, with blade increase of the cutting tool, the tool progress inside the tube decreases and the maximum force and the force variations enhance. Moreover, thickness variations of the cutting blade don't have much effect on the crushing force efficiency. Blade shape of the cutting tool has great effect during impact and can vary the energy absorption parameters, significantly. The tool shape must be designed and checked based on the required range to be assured of the results. Also, energy absorption parameters of the rupture are better than crushing during the impact process. It seems that the multiobjective optimization method is required for considering the tube impact conditions to obtain length, thickness, diameter and proper material of the tube as an energy absorber. Also, the multi-objective optimization seems necessary for obtaining the number of cutting edges, the thickness of edges and the tools' depth.

\section{References}

1. Zhou, Y.; Lan, F.; Chen, J. 2011. Crashworthiness research on S-shaped front rails made of steel-aluminum hybrid materials, Thin-Walled Structures 49(2) 291297. http://dx.doi.org/10.1016/j.tws.2010.10.007.

2. Lu, G.; Yu, T. 2003. Energy Absorption of Structures and Materials, Elsevier, 424 p.

3. Association, E.A. 2008. Aluminum in cars; Technical report. Available online at http://www.eaa.net/upl/4/en/ doc/Aluminium in cars.
4. Alavi Nia, A.; Haddad Hamedani, J. 2010. Comparative analysis of energy absorption and deformations of thin walled tubes with various section geometries, ThinWalled Structures 48(12): 946-954. http://dx.doi.org/10.1016/j.tws.2010.07.003.

5. Reid, S. 1993. Plastic deformation mechanisms in axially compressed metal tubes used as impact energy absorbers, International Journal of Mechanical Sciences 35(12): 1035-1052. http://dx.doi.org/10.1016/0020-7403(93)90054-X.

6. Zhou, X.; Wang, J. 2005. Study on the coalescence mechanism of splitting failure of crack-weakened rock subjected to compressive loads, Mechanics Research Communications 32(2): 161-171.

http://dx.doi.org/10.1016/j.mechrescom.2004.06.003.

7. Cheng, Q.; Altenhof, W. 2005. Load/displacement and energy absorption performances of AA6061-T6 tubes under a cutting deformation mode, International Journal of Crashworthiness 10(6): 621-633. http://dx.doi.org/10.1533/ijcr.2005.0376.

8. Yi Jin, S.; Altenhof, W.; Kapoor, T. 2006. An experimental investigation into the cutting deformation mode of AA6061-T6 round extrusions, Thin-Walled Structures 44(7): 773-786. http://dx.doi.org/10.1016/j.tws.2006.05.009.

9. Majumder, A.; Altenhof, W.; Vijayan, V.; Jin, S.Y. 2008. Quasi-static axial cutting of AA6061 T4 and T6 round extrusions, Proceedings of the Institution of Mechanical Engineers, Part L: Journal of Materials Design and Applications 222(3): 183-195. http://dx.doi.org/10.1243/14644207JMDA170.

10. Jin, S.Y.; Altenhof, W. 2011. An analytical model on the steady-state deformation of circular tubes under an axial cutting deformation mode, International Journal of Solids and Structures 48(2): 269-279. 
http://dx.doi.org/10.1016/j.ijsolstr.2010.10.001.

11. Chung Kim Yuen, S.; Altenhof, W.; Opperman, C.; Nurick, G. 2013. Axial splitting of circular tubes by means of blast load, International Journal of Impact Engineering 53: 17-28. http://dx.doi.org/10.1016/j.ijimpeng.2012.09.003.

12. Niknejad, A.; Rezaei, B.; Liaghat, G. H. 2013. Empty circular metal tubes in the splitting process-theoretical and experimental studies, Thin-Walled Structures 72: $48-60$. http://dx.doi.org/10.1016/j.tws.2013.06.015.

13. Marzbanrad, J.; Keshavarzi, A.; Aboutalebi, F.H. 2014. Influence of elastic and plastic support on the energy absorption of the extruded aluminium tube using ductile failure criterion, International Journal of Crashworthiness 19(2) -172-181. http://dx.doi.org/10.1080/13588265.2014.883678.

14. Hooputra, H.; Gese, H.; Dell, H.; Werner, H. 2004. A comprehensive failure model for crashworthiness simulation of aluminium extrusions, International Journal of Crashworthiness 9(5): 449-464. http://dx.doi.org/10.1533/ijcr.2004.0289.

15. Kolmogorov, W. 1970. Spannungen Deformationen Bruch, Metallurgija, $230 \mathrm{p}$.

16. Hill, M.R.; Panontin, T.L. 2002. Micromechanical modelling of fracture initiation in 7050 aluminum, Engineering Fracture Mechanics 6(18): 2163-2186. http://dx.doi.org/10.1016/S0013-7944(01)00148-5.

17. Marzbanrad, J.; Keshavarzi, A. 2014. A Numerical and experimental study on the crash behavior of the extruded aluminum crash box with elastic support, Latin American Journal of Solids and Structures 11(8): 13291348.

http://dx.doi.org/10.1590/S1679-78252014000800003.
B. Mashadi, J. Marzbanrad, A. Afkar

\section{BLADE SHAPE AND THICKNESS INFLUENCE OF MULTI-BLADE CUTTING TOOL DURING AXIAL IMPACT TO THE EXTRUDED ALUMINUM TUBE}

S u m m a r y

Thin-walled structures, like crash boxes, may be used as energy absorbers in the automotive chassis. There have been lots of investigations about the behavior of these parts during frontal crashes. Previous researches show that thin-walled circular tube has the highest energy absorption among different structures. In this study, numerical modeling of the aluminum alloy tube is done using a 4-blades cutting tool which inserts an impact to the tube with the velocity of $10 \mathrm{~m} / \mathrm{s}$. The modeling is performed based on the comprehensive damage criterion of Hooputra. By using this modeling, the effects of 4-blades tool with different cutting blade's shapes and thicknesses on effective parameters of energy absorption including maximum displacement, maximum force, specific energy absorption and crushing force efficiency are investigated. The obtained results show that the effects of shape and thickness of the cutting tool blades cannot be neglected and a multi-purpose optimization is needed for proper tool design according to the customer requirements.

Keywords: thin-walled structure, energy absorption, cutting tool, axial impact.

Received January 08, 2016

Accepted May 11, 2016 